\title{
Antiviral Treatment for Hepatitis C Virus Infection after Liver Transplantation
}

\author{
Yasuhiko Sugawara, Sumihito Tamura, and Norihiro Kokudo \\ Artificial Organ and Transplantation Division, Department of Surgery, Graduate School of Medicine, University of Tokyo, 7-3-1 Hongo, \\ Bunkyo-ku, Tokyo 113-8655, Japan \\ Correspondence should be addressed to Yasuhiko Sugawara, yasusugatky@yahoo.co.jp
}

Received 21 May 2010; Revised 13 August 2010; Accepted 6 October 2010

Academic Editor: Tatehiro Kagawa

Copyright (๑) 2010 Yasuhiko Sugawara et al. This is an open access article distributed under the Creative Commons Attribution License, which permits unrestricted use, distribution, and reproduction in any medium, provided the original work is properly cited.

\begin{abstract}
A significant proportion of patients with chronic hepatitis $\mathrm{C}$ virus (HCV) infection develop liver cirrhosis and complications of end-stage liver disease over two to three decades and require liver transplantation, however, reinfection is common and leads to further adverse events under immunosuppression. Pretransplant antiviral or preemptive therapy is limited to mildly decompensated patients due to poor tolerance. The mainstay of management represents directed antiviral therapy after evidence of recurrence of chronic hepatitis C. Combined pegylated interferon and ribavirin therapy is the current standard treatment with sustained viral response rates of $25 \%$ to $45 \%$. The rate is lower than that in the immunocompetent population, partly due to the high prevalence of intolerability. To date, there is no general consensus regarding the antiviral treatment modality, timing, or dosing for HCV in patients with advanced liver disease and after liver transplantation. New anti-HCV drugs to delay disease progression or to enhance viral clearance are necessary.
\end{abstract}

\section{Introduction}

According to the World Health Organization, 130 to 170 million people are chronically infected with hepatitis $\mathrm{C}$ virus (HCV) and 3 to 4 million people are newly infected each year worldwide [1]. The median time to develop cirrhosis is estimated to be 30 years, and $33 \%$ of patients have an expected median time to the development of cirrhosis of less than 20 years. Although antiviral therapy is available, the number of patients with end-stage liver disease due to $\mathrm{HCV}$ will continue rise over the next 10 years [2]. HCV is the major cause of chronic liver disease, cirrhosis, and liver cancer in most developed countries [3], including Japan [4]. It is the most common indication for liver transplantation in developed nations $[5,6]$.

Liver transplantation is an effective treatment to reduce morbidity and mortality in this population. Reinfection with $\mathrm{HCV}$, however, is a critical complication with major effects on graft and patient survival. Indeed, the real challenge of controlling HCV begins after liver transplantation under lifelong immunosuppression, and mitigating the damage is a crucial concern. In this paper, we focus on this challenging aspect, evaluating the available treatment options and strategies against HCV before and after transplantation to prevent reinfection with the goal of eradicating recurrent infection.

\section{Clinical Course after Liver Transplantation}

Spontaneous clearance of HCV after transplantation is rare [7-11], and reinfection of the allograft is common [12, 13]. Histologic progression of $\mathrm{HCV}$ under immunosuppressive therapy is more rapid than that in nontransplant patients $[14,15]$. HCV patients have a poorer prognosis after liver transplantation than those with other indications [16-19], a finding that remains unchanged in recent research [20]. Large studies have demonstrated that recipients with $\mathrm{HCV}$ have approximately 10\% lower 5-year graft and patient survival rates than non-HCV controls $[18,19]$. One study comparing approximately $7500 \mathrm{HCV}$ recipients and 20,000 non-HCV recipients reported an overall 3-year patient survival rate of $79 \%$ in HCV patients and $81 \%$ in nonHCV patients [16]. Factors with a significant negative impact 
on patient survival include a preoperative model for endstage liver disease (MELD) score [21], fibrosis stage of 2 or greater at 12-month biopsy, advanced donor age, history of hepatocellular carcinoma (HCC), and early acute rejection [22].

$\mathrm{HCV}$ reinfection occurs during transplantation in the reperfusion phase of the graft, and acute hepatitis can usually be detected 1 to 3 months after transplantation [23]. The clinical course following reinfection varies. In general, $8 \%$ to $30 \%$ of the recipients will present with severe progressive disease within 5 years $[15,17,24]$. The median time to cirrhosis in the nontransplant patients was 30 years [25] and in the transplanted patients with HCV disease is expected to be 10 years. The risk of decompensation is $50 \%$ within 1 year after diagnosis in the absence of therapeutic intervention $[15,26]$. A small percentage of recipients can develop an early cholestatic hepatitis within the first year after transplantation with a risk $(2 \%-8 \%)$ of progressive liver dysfunction and rapid development of cirrhosis [12, 27]. Retransplantation in these patients is associated with poor outcomes and is controversial [28].

\section{Risk Factors for Severe Recurrent HCV}

The reported risk factors include advanced donor age [29, $30]$, high viral load in the preoperative or early postoperative periods [31, 32], treatment of acute rejection [28], long duration between the antiviral therapy and transplantation $[16,18,33]$, and baseline pre transplant liver function [34]. The expression of cytokeratin 19 and that of vimentin in liver biopsies without fibrotic changes (F0) [35] are also considered risk factors for severe recurrent HCV. Postoperative insulin resistance diabetes mellitus [36, 37], metabolic syndrome [38], and lipid peroxidation (oxidative degradation of lipids) [39] are reported to be associated with severe HCV recurrence.

The role of corticosteroids in severe recurrent $\mathrm{HCV}$ is complicated. Steroid bolus injection as acute rejection therapy is one of the risk factors for severe HCV recurrence and graft loss [19]. Rapid withdrawal of corticosteroids might cause graft fibrosis [40], but a corticoid-free regimen may be promising [41]. A meta-analysis of randomized trials using a corticoid-free immunosuppression regimen showed a significant reduction of HCV recurrence in corticoid-free groups [42].

The impact of other immunosuppressive agents, including mycophenolate mofetil, azathioprine [43], or interleukin-2 inhibitors [44] on severe recurrent $\mathrm{HCV}$ remains controversial. OKT3 is associated with increased graft loss and increased mortality [12].

A viral quasispecies is a group of viruses related by a similar mutation or mutations, competing within a highly mutagenic environment. After transplantation, diversification of hypervariable region 1 is decreased, and the virus population becomes more homologous [45] although the changes might be temporary [46]. A more complex HCV hypervariable region 1 quasispecies population was reported to be associated with $\mathrm{HCV}$ recurrence after transplantation $[47,48]$.

\section{Viral Kinetics}

Powers et al. [49] confirmed that viral loads begin to rise 15 hours after the anhepatic phase. In total, 19\% hepatocytes are infected in an average of 37 days (range: 4-82 days) after transplantation. Schiano et al. [50] demonstrated accelerated HCV kinetics in LDLT recipients $(n=11)$ compared to deceased donor liver transplantation (DDLT) recipients $(n=$ 15). In their study, HCV RNA levels rose more rapidly in LDLT patients; the differences in patient and graft survival, however, did not reach statistical significance.

Another study [51] focusing on the histologic aspects of $\mathrm{HCV}$ recurrence with protocol biopsy reported more severe progression of $\mathrm{HCV}$ disease in LDLT compared to DDLT. Other studies $[52,53]$ have also demonstrated that individuals with a high level of replication in the perioperative period develop more fibrosis in the allograft 1 year after transplantation. When the graft develops fibrotic or cirrhotic changes, the patient prognosis is dismal.

\section{Pretransplant Antiviral Therapy}

Antiviral treatment of patients with mildly decompensated cirrhosis (model for end-stage liver disease, MELD > 18) is a more problematic approach than treatment after transplantation.

Suitable candidates for pretransplant therapy would be treatment-naïve patients or prior relapsers to standard interferon (IFN) and ribavirin (RBV) treatment because the chances for an on-treatment virologic response before transplantation are high [27]. Patients with predictable timing of transplantation such as those with living donors or those with HCC may be good candidates for pre-transplant therapy. The use of growth factors is considered an option to treat therapy-associated anemia and leucopenia as it can improve quality of life and may decrease the need for antiviral therapy dose reduction [54].

Everson et al. [55] reported his experience in the treatment of 102 patients with chronic hepatitis and decompensated liver disease using a low accelerating dosage regimen of IFN alfa-2b plus RBV. Serum HCV RNA was cleared in approximately $40 \%$ of patients on this treatment, and $22 \%$ achieved a sustained virologic response (SVR).

Forns et al. [56] administered antiviral therapy to patients with IFN alpha-2b $3 \mathrm{MU} /$ day and RBV $800 \mathrm{mg} /$ day when the expected time until transplantation was less than 4 months. Of 30 patients enrolled, 9 (30\%) achieved a virologic response and 21 did not respond to therapy. Of the nine, six remained free of infection after a median followup of 46 weeks and HCV infection recurred in three patients after transplantation. In contrast, Smallwood et al. [57] reported that patients treated with IFN before transplantation have a significantly earlier and more aggressive recurrence of $\mathrm{HCV}$. Carrión et al. [58] performed a case control study comparing 51 patients who underwent treatment with IFN and RBV and a control group (untreated 51 individuals awaiting transplantation who were matched by age, Child-Pugh, and time on the waiting list). There was a higher incidence of bacterial infections after transplantation in treated patients, 
particularly in Child-Pugh B-C individuals. Further data are needed before a definitive conclusion can be drawn.

\section{Early Posttransplant Antiviral (Preemptive) Therapy}

6.1. Its Rationale and Use in LDLT Patients. Preemptive treatment may be beneficial in potentially tolerant patients, such as patients with a lower natural MELD score undergoing liver transplantation for HCC within the Milan criteria, with an outcome comparable to that of non-HCC cases, and also in well-planned LDLT cases [59] with splenectomy [60]. The preemptive approach may provide an oncologic benefit, which has been demonstrated in nontransplant patients with HCV who underwent liver resection for HCC [61].

The rationale for preemptive therapy is to strike at a time when the total HCV viral load is relatively low after liver transplantation [23,49] and histologic damage is absent or minimal. Delay of histologic damage can be expected [62, 63]. Garcia-Retortillo et al. [23] observed a rapid decrease in the viral load during the anhepatic phase in 20 patients who underwent liver transplantation for HCV. The viral load continued to exponentially decrease after graft reperfusion with a progressive increase after the first week of transplantation, reaching a plateau by the end of the first month.

We examined the feasibility and efficacy of a preemptive combination of IFN and RBV therapy against HCV in LDLT patients [64]. Tolerance was a limiting factor, with $25 \%$ of the patients deviating from the planned protocol. Overall, among the 23 patients enrolled, 9 (39\%) achieved SVR. The cumulative 3-year survival rate did not differ between the enrolled patients and the HCV-negative patients (90\%) during the study period [59]. The results of the study were encouraging and demonstrated an optimal window for treatment initiation and the optimal doses of IFN and RBV necessary for effective viral eradication [65] after LDLT.

6.2. In DDLT. The overall efficacy and feasibility of preemptive therapy in DDLT is controversial. Randomized studies on a preemptive approach with IFN monotherapy $[66,67]$ or combined therapy [63] demonstrated a reduced or delayed incidence of hepatitis after liver transplantation, but not the prevention of viremia. Discontinuation of the treatment was necessary in $30 \%$ of the subjects in the study. Mazzaferro et al. [68] treated 36 recipients with IFN-alpha2b (3 million IU, 3 times/week) and RBV ( $10 \mathrm{mg} / \mathrm{kg}$ per day). The treatment was initiated at a median of 18 days after the operation and continued for a year. After a median followup of 52 months, 5 -year patient survival was $88 \%$. Serum HCV RNA was cleared in 12 patients of the 36 recipients (33\%) after a median of 37 days. These patients remained negative for serum HCV RNA for a median of 36 additional months without antiviral treatment. Dose reduction was necessary in 9 (25\%) patients. Although these outcomes were encouraging, the current understanding is that the adverse events associated with treatment outweigh the theoretical benefits of preemptive therapy [12].
Shergill et al. [69] reported about the results of preemptive treatment. Only $51(41 \%)$ of 124 transplant recipients were eligible for preemptive treatment; eligible patients had lower MELD and Child-Pugh scores pretransplantation. Dose reductions and discontinuations were required in $85 \%$ and $37 \%$ of patients, respectively, and $27 \%$ experienced serious adverse events. Only $15 \%$ of patients were able to achieve full-dose treatment during treatment. End-oftreatment rate and SVR were $14 \%$ and $9 \%$, respectively.

\section{Treatment for Established Infection}

The recommendation of the International Liver Transplantation Society is to perform post-transplant surveillance and protocol biopsies to detect recurrent HCV disease [70] and to start combined pegylated-(peg-) IFN and RBV therapy for stage II fibrosis [12]. Treatment of HCV recurrence is mostly modeled after the strategy of treating HCV in nontransplant patients [5, 6]: Studies of a noncontrolled series of patients [71-81] revealed an efficacy of $26 \%$ to $50 \%$ after peg-IFN and RBV therapy, a higher efficacy than that of conventional IFN and RBV therapy.

These studies suggested that factors associated with higher probabilities of a viral response were nongenotype 1, low pretreatment HCV RNA levels, absence of advanced cirrhosis, early virologic response $(\geq 2 \log$ drop in HCV RNA from baseline at 3 months), and adherence to combination therapy [71, 82-93] similar to that in nontransplant patients. Other reports $[90,94]$ suggested that patients on cyclosporine had a higher SVR. Berenguer et al. [73] reported a higher SVR rate for nongenotype $1(60 \%)$ versus genotype $1(31 \%)$ and a higher SVR rate with peg-IFN with RBV compared to standard IFN with RBV (50\% versus $13 \%)$. Combined treatment with peg-IFN is suggested to be effective among those who failed previous conventional IFN and RBV therapy, achieving an SVR in 30\% with histologic improvement [95]. These studies were, however, limited by small sample sizes and a lack of randomized controlled trials.

Carrión et al. [96] studied patients with mild HCV recurrence (fibrosis stage F0-2) that were randomized into two groups; group A, no treatment; group B, treated with combined peg-IFN-alpha-2b $(1.5 \mu \mathrm{g} / \mathrm{kg} /$ week $)$ and RBV (adjusted for renal function, maximum dose $1200 \mathrm{mg} /$ day) for 48 weeks. Median time to treatment was 14 months. An SVR was achieved in $0(0 \%)$ and $13(48 \%)$, respectively. Histologic stabilization or improvement, which corresponded with improvement in the hepatic venous pressure gradient, was recognized with an SVR. Early virologic response was an independent significant factor predicting SVR in the study, as described previously [97-99]. Dose reduction was necessary in $67 \%$ of cases, and interruption was necessary in $56 \%$. An increased risk of rejection in the treatment groups was not substantiated. The study demonstrated the advantage of antiviral treatment with peg-IFN and RBV, which achieves permanent viral clearance in a high proportion of patients when initiated at the stage of mild HCV recurrence.

One systematic review [100] of the efficacy of posttransplant treatment with standard IFN (IFN-RBV) [93, 101-117] or peg-IFN in combination with RBV (peg-RBV) 
[77-80, 118-120] given for 6 to 12 months included 38 studies. Patients were predominantly men with a high rate of genotype 1 infection (> 80\%). IFN-RBV was associated with an end-of-treatment virologic response rate of $34 \%$ and an SVR rate of $24 \%$, while peg-RBV was associated with an endof-treatment virologic response rate of $42 \%$ and an SVR rate of $27 \%$. Pooled discontinuation rates were $24 \%$ with IFNRBV and $26 \%$ with peg-RBV. Only $33 \%$ with IFN-RBV and $21 \%$ with peg-RBV completed the intended protocol. The majority of patients required dose reduction. The overall rate of acute graft rejection was 2\% with IFN-RBV and 5\% with peg-RBV. The authors concluded that combination therapies have similar tolerability and safety, but the advantage of peg$\mathrm{RBV}$ in terms of viral response remains unclear, and further studies are required.

Another systematic review [121] focused only on studies using peg-IFN in combination with RBV as post-transplant treatment. The 19 reviewed studies showed a mean endof-treatment response of $42 \%$ and a mean overall SVR of $30 \%$. A recent study [122] disclosed an SVR rate of $64 \%$ in DDLT patients. The antiviral treatment regimen comprised pegylated-IFN $(180 \mu \mathrm{g})$ every 2 weeks and RBV at a dose of 200 to $400 \mathrm{mg}$ every day. The treatment duration was flexible and individualized, and it depended on the viral response to treatment. The dosage of tacrolimus was decreased gradually.

\section{Nonresponders}

When an SVR cannot be achieved, the next possible best step is to prevent the progression of fibrosis. Peg-IFN may be histologically beneficial even when HCV eradication is not obtained $[123,124]$. Studies of nonresponders to determine the optimal dosage and duration of either IFN, RBV, or both are lacking in terms of delayed disease progression. Administration of oral ursodeoxycholic acid may be beneficial in terms of improving the biochemical response, but not histologic changes, as recently demonstrated in a largescale, multicenter, double-blind trial in a nontransplant population [125]. It has no clear benefits in liver transplant recipients [126].

In a subset of patients with a progressive cholestatic variant of HCV disease [127] despite combined IFN and RBV therapy, indefinite continuation of antiviral therapy [128], or temporary treatment with double-filtration plasmapheresis $[129,130]$, a novel option to decrease HCV viral load, in combination with antiviral therapy may be effective [130]. Further studies focusing on the long-term risks and benefits of various treatment modalities for patients nonresponsive to antiviral therapy are necessary.

\section{Future Perspectives}

Previous descriptions [131] as well as the descriptions above indicate the need for additional treatment modalities. The treatment goal should be eventual viral eradication. In theory, this goal can be achieved by disrupting the steadystate HCV kinetics by reducing virion production, thereby allowing infected cells to be eliminated [132, 133]. Lang
[134] classifies the future drugs currently under investigation into four categories: new IFNs, RBV alternatives, specific $\mathrm{HCV}$ inhibitors, and immunomodulators. Some of these drugs are in phase III trials awaiting further clinical evaluation.

As tolerability is the primary problem of the current widely applied combined IFN and RBV treatment after liver transplantation, specific HCV life-cycle inhibitors may have a beneficial role. Among the various drugs under investigation, protease inhibitors such as telaprevir and boceprevir appear to be safe and are currently undergoing clinical evaluation. A clinical trial with triple combinations of peg-IFN, RBV, and telaprevir has been performed [135] in patients with chronic HCV. The SVRs of the patients administered telaprevir for 24 and 48 weeks were $61 \%$ and $67 \%$, respectively. High SVR was obtained in patients who had not had a sustained response to the therapy with peg-IFN and RBV [136]. The SVR of the control patients (peg-IFN and RBV for 48 weeks) was $41 \%$. A phase-III clinical trial of boceprevir was begun in 2008 [137-140]. None of the new anti-HCV drugs, however, are currently being evaluated in HCV-infected liver transplant recipients.

\section{Conclusions}

HCV continues to be a major challenge in liver transplantation. Reinfection is common after transplantation, and progression of the disease leads to a dismal outcome. Pretransplant antiviral therapy with at least on-treatment virologic response at the time of transplantation would be desirable, but the tolerability and risk of therapy limits the applicability to patients with compensated or mildly decompensated liver disease (low MELD score). Preemptive treatment is also limited by frequent complications in the early post-transplant phase and a high rate of side effects. The use of combined peg-IFN and RBV therapy has increased the rate of viral clearance, but its intolerability in the majority of patients prevents its general application. The overall risk and benefit of the current strategy over the long term remains to be evaluated. Additional modalities combining new drugs, such as protease inhibitors, should be pursued.
Abbreviations
DDLT: deceased donor liver transplantation
HCC: hepatocellular carcinoma
HCV: hepatitis $\mathrm{C}$ virus
INF: interferon
LDLT: living donor liver transplantation
MELD: model for end stage liver disease
Peg-IFN: pegylated interferon
SVR: $\quad$ sustained viral response
RBV: ribavirin.

\section{Conflict of Interest}

None declared. 


\section{Acknowledgment}

The study was supported by a Grant-in-aid for Scientific Research from the Ministry of Education, Culture, Sports, Science and Technology of Japan.

\section{References}

[1] S. Tamura and Y. Sugawara, "Treatment strategy for hepatitis C after liver transplantation," Journal of Hepato-BiliaryPancreatic Surgery, vol. 15, no. 2, pp. 111-123, 2008.

[2] D. Lavanchy, "The global burden of hepatitis C," Liver International, vol. 29, no. 1, pp. 74-81, 2009.

[3] G. M. Lauer and B. D. Walker, "Hepatitis C virus infection," The New England Journal of Medicine, vol. 345, no. 1, pp. 4152, 2001.

[4] K. Kiyosawa, T. Umemura, T. Ichijo et al., "Hepatocellular carcinoma: recent trends in Japan," Gastroenterology, vol. 127, no. 5, supplement 1, pp. S17-S26, 2004.

[5] J. H. Hoofnagle and L. B. Seeff, "Peginterferon and ribavirin for chronic hepatitis C," The New England Journal of Medicine, vol. 355, no. 23, pp. 2444-2451, 2006.

[6] M. P. Manns, H. Wedemeyer, and M. Cornberg, "Treating viral hepatitis C: efficacy, side effects, and complications," Gut, vol. 55, no. 9, pp. 1350-1359, 2006.

[7] C. H. Dale, P. Burns, M. McCutcheon, R. HernandezAlejandro, and P. J. Marotta, "Spontaneous clearance of hepatitis C after liver and renal transplantation," Canadian Journal of Gastroenterology, vol. 23, no. 4, pp. 265-267, 2009.

[8] P. V. Suneetha, I. Mederacke, A. Heim et al., "Spontaneous clearance of chronic hepatitis $\mathrm{C}$ after liver transplantation: are hepatitis C virus-specific T cell responses the clue?" Liver Transplantation, vol. 14, no. 8, pp. 1225-1227, 2008.

[9] V. Bhagat, J. A. Foont, E. R. Schiff, and A. Regev, "Spontaneous clearance of hepatitis $\mathrm{C}$ virus after liver transplantation in two patients coinfected with hepatitis $\mathrm{C}$ virus and human immunodeficiency virus," Liver Transplantation, vol. 14, no. 1, pp. 92-95, 2008.

[10] D. N. Samonakis, E. Cholongitas, C. K. Triantos et al., "Sustained, spontaneous disappearance of serum HCV-RNA under immunosuppression after liver transplantion for HCV cirrhosis," Journal of Hepatology, vol. 43, no. 6, pp. 10911093, 2005.

[11] A. L. Doughty, A. Zekry, J. D. Spencer, S. Turhan, D. Painter, and G. W. McCaughan, "Spontaneous clearance of hepatitis $\mathrm{C}$ virus infection post-liver transplantation is associated with rapidly changing quasispecies: a single case report," Liver Transplantation, vol. 6, no. 5, pp. 648-653, 2000.

[12] R. H. Wiesner, M. Sorrell, F. Villamil et al., "Report of the first International Liver Transplantation Society expert panel consensus conference on liver transplantation and hepatitis C," Liver Transplantation, vol. 9, no. 11, pp. S1-S9, 2003.

[13] M. Berenguer, F. X. López-Labrador, and T. L. Wright, "Hepatitis C and liver transplantation," Journal of Hepatology, vol. 35, no. 5, pp. 666-678, 2001.

[14] N. Yilmaz, M. L. Shiffman, R. T. Stravitz et al., "A prospective evaluation of fibrosis progression in patients with recurrent hepatitis C virus following liver transplantation," Liver Transplantation, vol. 13, no. 7, pp. 975-983, 2007.

[15] M. Berenguer, L. Ferrell, J. Watson et al., "HCV-related fibrosis progression following liver transplantation: increase in recent years," Journal of Hepatology, vol. 32, no. 4, pp. 673$684,2000$.
[16] P. J. Thuluvath, K. L. Krok, D. L. Segev, and H. Y. Yoo, "Trends in post-liver transplant survival in patients with hepatitis C between 1991 and 2001 in the United States," Liver Transplantation, vol. 13, no. 5, pp. 719-724, 2007.

[17] D. Samuel, X. Forns, M. Berenguer et al., "Report of the monothematic EASL conference on liver transplantation for viral hepatitis (Paris, France, January 12-14, 2006)," Journal of Hepatology, vol. 45, no. 1, pp. 127-143, 2006.

[18] D. J. Mutimer, B. Gunson, J. Chen et al., "Impact of donor age and year of transplantation on graft and patient survival following liver transplantation for hepatitis C virus," Transplantation, vol. 81, no. 1, pp. 7-14, 2006.

[19] L. M. Forman, J. D. Lewis, J. A. Berlin, H. I. Feldman, and M. R. Lucey, "The association between hepatitis C infection and survival after orthotopic liver transplantation," Gastroenterology, vol. 122, no. 4, pp. 889-896, 2002.

[20] G. W. McCaughan, N. A. Shackel, S. I. Strasser, P. Dilworth, and P. Tang, "Minimal but significant improvement in survival for non-hepatitis C-related adult liver transplant patients beyond the one-year posttransplant mark," Liver Transplantation, vol. 16, no. 2, pp. 130-137, 2010.

[21] R. J. Firpi, V. Clark, C. Soldevila-Pico et al., "The natural history of hepatitis C cirrhosis after liver transplantation," Liver Transplantation, vol. 15, no. 9, pp. 1063-1071, 2009.

[22] J. F. Gallegos-Orozco, A. Yosephy, B. Noble et al., "Natural history of post-liver transplantation hepatitis C: a review of factors that may influence its course," Liver Transplantation, vol. 15, no. 12, pp. 1872-1881, 2009.

[23] M. Garcia-Retortillo, X. Forns, A. Feliu et al., "Hepatitis C virus kinetics during and immediately after liver transplantation," Hepatology, vol. 35, no. 3, pp. 680-687, 2002.

[24] E. J. Gane, B. G. Portmann, N. V. Naoumov et al., "Long-term outcome of hepatitis C infection after liver transplantation," The New England Journal of Medicine, vol. 334, no. 13, pp. 815-820, 1996.

[25] T. Poynard, P. Bedossa, and P. Opolon, "Natural history of liver fibrosis progression in patients with chronic hepatitis C," The Lancet, vol. 349, no. 9055, pp. 825-832, 1997.

[26] M. Berenguer, M. Prieto, J. M. Rayón et al., "Natural history of clinically compensated hepatitis C virus-related graft cirrhosis after liver transplantation," Hepatology, vol. 32, no. 4, part 1, pp. 852-858, 2000.

[27] J. Peveling-Oberhag, S. Zeuzem, and W. P. Hofmann, "Antiviral therapy of chronic hepatitis $\mathrm{C}$ in patients with advanced liver disease and after liver transplantation," Medical Microbiology and Immunology, vol. 199, no. 1, pp. 1-10, 2010.

[28] G. W. McCaughan and A. Zekry, "Mechanisms of HCV reinfection and allograft damage after liver transplantation," Journal of Hepatology, vol. 40, no. 3, pp. 368-374, 2004.

[29] U. P. Neumann, T. Berg, M. Bahra et al., "Fibrosis progression after liver transplantation in patients with recurrent hepatitis C," Journal of Hepatology, vol. 41, no. 5, pp. 830-836, 2004.

[30] M. Berenguer, M. Prieto, F. S. Juan et al., "Contribution of donor age to the recent decrease in patient survival among HCV-infected liver transplant recipients," Hepatology, vol. 36, no. 1, pp. 202-210, 2002.

[31] B. Roche and D. Samuel, "Risk factors for hepatitis C recurrence after liver transplantation," Journal of Viral Hepatitis, vol. 14, supplement 1, pp. 89-96, 2007.

[32] N. A. Shackel, J. Jamias, W. Rahman et al., "Early high peak hepatitis C viral load levels independently predict hepatitis C-related liver failure post-liver transplantation," Liver Transplantation, vol. 15, no. 7, pp. 709-718, 2009. 
[33] L. S. Belli, A. K. Burroughs, P. Burra et al., "Liver transplantation for HCV cirrhosis: Improved survival in recent years and increased severity of recurrent disease in female recipients: results of a long term retrospective study," Liver Transplantation, vol. 13, no. 5, pp. 733-740, 2007.

[34] M. Berenguer, V. Aguilera, M. Prieto et al., "Worse recent efficacy of antiviral therapy in liver transplant recipients with recurrent hepatitis C: impact of donor age and baseline cirrhosis," Liver Transplantation, vol. 15, no. 7, pp. 738-746, 2009.

[35] Z. Meriden, K. A. Forde, T. L. Pasha et al., "Histologic predictors of fibrosis progression in liver allografts in patients with hepatitis C virus infection," Clinical Gastroenterology and Hepatology, vol. 8, no. 3, pp. 289-296, 2010.

[36] B. J. Veldt, J. J. Poterucha, K. D. S. Watt et al., "Insulin resistance, serum adipokines and risk of fibrosis progression in patients transplanted for hepatitis C," American Journal of Transplantation, vol. 9, no. 6, pp. 1406-1413, 2009.

[37] S. Sabharwal, A. Delgado-Borrego, and R. T. Chung, "Extrahepatic hepatitis $\mathrm{C}$ virus after transplantation: diabetes and renal dysfunction," Liver Transplantation, vol. 14, supplement 1, pp. S51-S57, 2008.

[38] I. A. Hanouneh, A. E. Feldstein, A. J. McCullough et al., "The significance of metabolic syndrome in the setting of recurrent hepatitis C after liver transplantation," Liver Transplantation, vol. 14, no. 9, pp. 1287-1293, 2008.

[39] J. Madill, B. M. Arendt, E. Aghdassi et al., "Hepatic lipid peroxidation and antioxidant micronutrients in hepatitis virus $\mathrm{C}$ liver recipients with and without disease recurrence," Transplantation Proceedings, vol. 41, no. 9, pp. 3800-3805, 2009.

[40] M. Berenguer, A. Royuela, and J. Zamora, "Immunosuppression with calcineurin inhibitors with respect to the outcome of HCV recurrence after liver transplantation: results of a meta-analysis," Liver Transplantation, vol. 13, no. 1, pp. 2129, 2007.

[41] S. Marubashi, K. Dono, H. Nagano et al., "Steroid-free living donor liver transplantation in adults: impact on hepatitis C recurrence," Clinical Transplantation, vol. 23, no. 6, pp. 904 913, 2009.

[42] D. L. Segev, S. M. Sozio, E. J. Shin et al., "Steroid avoidance in liver transplantation: meta-analysis and meta-regression of randomized trials," Liver Transplantation, vol. 14, no. 4, pp. 512-525, 2008.

[43] P. Manousou, D. Samonakis, E. Cholongitas et al., "Outcome of recurrent hepatitis $\mathrm{C}$ virus after liver transplantation in a randomized trial of tacrolimus monotherapy versus triple therapy," Liver Transplantation, vol. 15, no. 12, pp. 17831791, 2009.

[44] D. K. Moonka, D. Kim, A. Kapke, K. A. Brown, and A. Yoshida, "The influence of induction therapy on graft and patient survival in patients with and without hepatitis $\mathrm{C}$ after liver transplantation," American Journal of Transplantation, vol. 10, no. 3, pp. 590-601, 2010.

[45] E. Schvoerer, E. Soulier, C. Royer et al., "Early evolution of hepatitis $\mathrm{C}$ virus (HCV) quasispecies after liver transplant for HCV-related disease," Journal of Infectious Diseases, vol. 196, no. 4, pp. 528-536, 2007.

[46] X. Fan and A. M. Di Bisceglie, "Diversification of hypervariable region 1 of hepatitis C virus after liver transplantation," Journal of Medical Virology, vol. 70, no. 2, pp. 212-218, 2003.

[47] A. C. Lyra, X. Fan, D. M. Lang et al., "Evolution of hepatitis C viral quasispecies after liver transplantation," Gastroenterology, vol. 123, no. 5, pp. 1485-1493, 2002.
[48] A. L. Doughty, D. M. Painter, and G. W. McCaughan, "Posttransplant quasispecies pattern remains stable over time in patients with recurrent cholestatic hepatitis due to hepatitis C virus," Journal of Hepatology, vol. 32, no. 1, pp. 126-134, 2000.

[49] K. A. Powers, R. M. Ribeiro, K. Patel et al., "Kinetics of hepatitis C virus reinfection after liver transplantation," Liver Transplantation, vol. 12, no. 2, pp. 207-216, 2006.

[50] T. D. Schiano, J. A. Gutierrez, J. L. Walewski et al., "Accelerated hepatitis $\mathrm{C}$ virus kinetics but similar survival rates in recipients of liver grafts from living versus deceased donors," Hepatology, vol. 42, no. 6, pp. 1420-1428, 2005.

[51] M. Garcia-Retortillo, X. Forns, J. M. Llovet et al., "Hepatitis $\mathrm{C}$ recurrence is more severe after living donor compared to cadaveric liver transplantation," Hepatology, vol. 40, no. 3, pp. 699-707, 2004.

[52] A. Massaguer, S. Ramírez, J. A. Carrión, P. González, J. M. Sánchez-Tapias, and X. Forns, "Evolution of the NS3 and NS5B regions of the hepatitis $\mathrm{C}$ virus during disease recurrence after liver transplantation," American Journal of Transplantation, vol. 7, no. 9, pp. 2172-2179, 2007.

[53] R. Sreekumar, A. Gonzalez-Koch, Y. Maor-Kendler et al., "Early identification of recipients with progressive histologic recurrence of hepatitis C after liver transplantation," Нераtology, vol. 32, no. 5, pp. 1125-1130, 2000.

[54] M. G. Ghany, D. B. Strader, D. L. Thomas, and L. B. Seeff, "Diagnosis, management, and treatment of hepatitis C: an update," Hepatology, vol. 49, no. 4, pp. 1335-1374, 2009.

[55] G. T. Everson, "Treatment of patients with hepatitis C virus on the waiting list," Liver Transplantation, vol. 9, no. 11, pp. S90-S94, 2003

[56] X. Forns, M. García-Retortillo, T. Serrano et al., "Antiviral therapy of patients with decompensated cirrhosis to prevent recurrence of hepatitis C after liver transplantation," Journal of Hepatology, vol. 39, no. 3, pp. 389-396, 2003.

[57] G. A. Smallwood, R. Devine, C. Fasola, A. C. Stieber, and T. G. Heffron, "Does interferon use prior to liver transplant influence hepatitis C outcomes following transplantation?" Transplantation, vol. 86, no. 12, pp. 1795-1798, 2008.

[58] J. A. Carrión, E. Martínez-Bauer, G. Crespo et al., "Antiviral therapy increases the risk of bacterial infections in HCVinfected cirrhotic patients awaiting liver transplantation: a retrospective study," Journal of Hepatology, vol. 50, no. 4, pp. 719-728, 2009.

[59] Y. Sugawara, M. Makuuchi, Y. Matsui et al., "Preemptive therapy for hepatitis $\mathrm{C}$ virus after living-donor liver transplantation," Transplantation, vol. 78, no. 9, pp. 1308-1311, 2004.

[60] Y. Kishi, Y. Sugawara, N. Akamatsu et al., "Splenectomy and preemptive interferon therapy for hepatitis C patients after living-donor liver transplantation," Clinical Transplantation, vol. 19, no. 6, pp. 769-772, 2005.

[61] A. Marzano, P. Lampertico, V. Mazzaferro et al., "Prophylaxis of hepatitis B virus recurrence after liver transplantation in carriers of lamivudine-resistant mutants," Liver Transplantation, vol. 11, no. 5, pp. 532-538, 2005.

[62] N. Chalasani, C. Manzarbeitia, P. Ferenci et al., "Peginterferon alfa-2a for hepatitis $\mathrm{C}$ after liver transplantation: two randomized, controlled trials," Hepatology, vol. 41, no. 2, pp. 289-298, 2005.

[63] A. Kuo, V. Tan, B. Lan et al., "Long-term histological effects of preemptive antiviral therapy in liver transplant recipients with hepatitis C virus infection," Liver Transplantation, vol. 14, no. 10, pp. 1491-1497, 2008. 
[64] S. Tamura, Y. Sugawara, N. Yamashiki, J. Kaneko, N. Kokudo, and M. Makuuchi, "Pre-emptive antiviral therapy in living donor liver transplantation for hepatitis C: observation based on a single-center experience," Transplant International, vol. 23, no. 6, pp. 580-588, 2010.

[65] N. A. Terrault, "Prophylactic and preemptive therapies for hepatitis C virus-infected patients undergoing liver transplantation," Liver Transplantation, vol. 9, no. 11, pp. S95S100, 2003.

[66] P. A. Sheiner, P. Boros, F. M. Klion et al., "The efficacy of prophylactic interferon alfa- $2 \mathrm{~b}$ in preventing recurrent hepatitis C after liver transplantation," Hepatology, vol. 28, no. 3, pp. 831-838, 1998.

[67] N. Singh, T. Gayowski, C. F. Wannstedt et al., "Interferon$\alpha$ for prophylaxis of recurrent viral hepatitis $\mathrm{C}$ in liver transplant recipients: a prospective, randomized, controlled trial," Transplantation, vol. 65, no. 1, pp. 82-86, 1998.

[68] V. Mazzaferro, A. Taggerb, M. Schiavo et al., "Prevention of recurrent hepatitis C after liver transplantation with early interferon and ribavirin treatment," Transplantation Proceedings, vol. 33, no. 1-2, pp. 1355-1357, 2001.

[69] A. K. Shergill, M. Khalili, S. Straley et al., "Applicability, tolerability and efficacy of preemptive antiviral therapy in hepatitis C-infected patients undergoing liver transplantation," American Journal of Transplantation, vol. 5, no. 1, pp. 118-124, 2005.

[70] R. J. Firpi, M. F. Abdelmalek, C. Soldevila-Pico et al., "Oneyear protocol liver biopsy can stratify fibrosis progression in liver transplant recipients with recurrent hepatitis C infection," Liver Transplantation, vol. 10, no. 10, pp. 12401247, 2004.

[71] I. A. Hanouneh, C. Miller, F. N. Aucejo, R. Lopez, M. K. Quinn, and N. N. Zein, "Recurrent hepatitis C after liver transplantation: on-treatment prediction of response to peginterferon/ribavirin therapy," Liver Transplantation, vol. 14 , no. 1 , pp. 53-58, 2008.

[72] I. Fernández, J. C. Meneu, F. Colina et al., "Clinical and histological efficacy of pegylated interferon and ribavirin therapy of recurrent hepatitis C after liver transplantation," Liver Transplantation, vol. 12, no. 12, pp. 1805-1812, 2006.

[73] M. Berenguer, A. Palau, A. Fernandez et al., "Efficacy, predictors of response, and potential risks associated with antiviral therapy in liver transplant recipients with recurrent hepatitis C," Liver Transplantation, vol. 12, no. 7, pp. 10671076, 2006.

[74] M. Biselli, P. Andreone, A. Gramenzi et al., "Pegylated interferon plus ribavirin for recurrent Hepatitis $\mathrm{C}$ infection after liver transplantation in naïve and non-responder patients on a stable immunosuppressive regimen," Digestive and Liver Disease, vol. 38, no. 1, pp. 27-32, 2006.

[75] E. Oton, R. Barcena, S. Garcia-Garzon et al., "Pegylated interferon and ribavirin for the recurrence of chronic hepatitis C genotype 1 in transplant patients," Transplantation Proceedings, vol. 37, no. 9, pp. 3963-3964, 2005.

[76] S. Mukherjee, "Pegylated interferon alfa-2a and ribavirin for recurrent hepatitis C after liver transplantation," Transplantation Proceedings, vol. 37, no. 10, pp. 4403-4405, 2005.

[77] L. Castells, V. Vargas, H. Allende et al., "Combined treatment with pegylated interferon $(\alpha-2 b)$ and ribavirin in the acute phase of hepatitis $\mathrm{C}$ virus recurrence after liver transplantation," Journal of Hepatology, vol. 43, no. 1, pp. 53-59, 2005.

[78] H. Rodriguez-Luna, A. Khatib, P. Sharma et al., “Treatment of recurrent hepatitis $\mathrm{C}$ infection after liver transplantation with combination of pegylated interferon $\alpha 2 b$ and ribavirin: an open-label series," Transplantation, vol. 77, no. 2, pp. 190194, 2004.

[79] J. Dumortier, J.-Y. Scoazec, P. Chevallier, and O. Boillot, "Treatment of recurrent hepatitis C after liver transplantation: a pilot study of peginterferon alfa-2b and ribavirin combination," Journal of Hepatology, vol. 40, no. 4, pp. 669674, 2004.

[80] S. Mukherjee, J. Rogge, L. Weaver, and D. F. Schafer, "Pilot study of pegylated interferon alfa- $2 b$ and ribavirin for recurrent hepatitis $\mathrm{C}$ after liver transplantation," Transplantation Proceedings, vol. 35, no. 8, pp. 3042-3044, 2003.

[81] Y. Ueda, Y. Takada, H. Marusawa, H. Egawa, S. Uemoto, and T. Chiba, "Individualized extension of pegylated interferon plus ribavirin therapy for recurrent hepatitis $\mathrm{C}$ genotype $1 \mathrm{~b}$ after living-donor liver transplantation," Transplantation, vol. 90, no. 6, pp. 661-665, 2010.

[82] S. J. Hadziyannis, H. Sette Jr., T. R. Morgan et al., "Peginterferon-alpha-2a and ribavirin combination therapy in chronic hepatitis C: a randomized study of treatment duration and ribavirin dose," Annals of Internal Medicine, vol. 140, no. 5, pp. 346-355, 2004.

[83] G. L. Davis, J. B. Wong, J. G. McHutchison, M. P. Manns, J. Harvey, and J. Albrecht, "Early virologic response to treatment with peginterferon alfa-2b plus ribavirin in patients with chronic hepatitis C," Hepatology, vol. 38, no. 3, pp. 645652, 2003.

[84] J. G. McHutchison, M. Manns, K. Patel et al., "Adherence to combination therapy enhances sustained response in genotype-1-infected patients with chronic hepatitis C," Gastroenterology, vol. 123, no. 4, pp. 1061-1069, 2002.

[85] M. W. Fried, M. L. Shiffman, K. Rajender Reddy et al., "Peginterferon alfa-2a plus ribavirin for chronic hepatitis C virus infection," The New England Journal of Medicine, vol. 347, no. 13, pp. 975-982, 2002.

[86] M. P. Manns, J. G. McHutchison, S. C. Gordon et al., "Peginterferon alfa-2b plus ribavirin compared with interferonalfa$2 \mathrm{~b}$ plus ribavirin for initial treatment of chronic hepatitis $\mathrm{C}$ : a randomised trial," The Lancet, vol. 358, no. 9286, pp. 958965, 2001.

[87] S. C. Schmidt, M. Bahra, S. Bayraktar et al., "Antiviral treatment of patients with recurrent hepatitis $\mathrm{C}$ after liver transplantation with pegylated interferon," Digestive Diseases and Sciences, vol. 55, no. 7, pp. 2063-2069, 2009.

[88] A. Jain, R. Sharma, C. Ryan et al., "Response to antiviral therapy in liver transplant recipients with recurrent hepatitis C viral infection: a single center experience," Clinical Transplantation, vol. 24, no. 1, pp. 104-111, 2010.

[89] S. Dinges, I. Morard, M. Heim et al., "Pegylated interferonalpha2a/ribavirin treatment of recurrent hepatitis C after liver transplantation," Transplant Infectious Disease, vol. 11, no. 1, pp. 33-39, 2009.

[90] M. Cescon, G. L. Grazi, A. Cucchetti et al., "Predictors of sustained virological response after antiviral treatment for hepatitis $\mathrm{C}$ recurrence following liver transplantation," Liver Transplantation, vol. 15, no. 7, pp. 782-789, 2009.

[91] B. Raziorrouh, M.-C. Jung, C. A. Schirren et al., "Antiviral therapy for recurrent hepatitis $\mathrm{C}$ after liver transplantation: sustained virologic response is related to genotype $2 / 3$ and response at week 12," European Journal of Gastroenterology and Hepatology, vol. 20, no. 8, pp. 778-783, 2008.

[92] E. Hörnfeldt, H. Gjertsen, and O. Weiland, "High adherence with a low initial ribavirin dose in combination with pegylated-IFN alpha-2a for treatment of recurrent hepatitis 
C after liver transplantation," Scandinavian Journal of Infectious Diseases, vol. 40, no. 3, pp. 259-265, 2008.

[93] D. Samuel, T. Bizollon, C. Feray et al., "Interferon- $\alpha$ 2b plus ribavirin in patients with chronic hepatitis $\mathrm{C}$ after liver transplantation: a randomized study," Gastroenterology, vol. 124, no. 3, pp. 642-650, 2003.

[94] N. Selzner, E. L. Renner, M. Selzner et al., "Antiviral treatment of recurrent Hepatitis $\mathrm{C}$ after liver transplantation: predictors of response and long-term outcome," Transplantation, vol. 88, no. 10, pp. 1214-1221, 2009.

[95] T. Bizollon, P. Pradat, J.-Y. Mabrut et al., "Histological benefit of retreatment by pegylated interferon alfa- $2 \mathrm{~b}$ and ribavirin in patients with recurrent hepatitis $C$ virus infection posttransplantation," American Journal of Transplantation, vol. 7, no. 2, pp. 448-453, 2007.

[96] J. A. Carrión, M. Navasa, M. García-Retortillo et al., "Efficacy of antiviral therapy on hepatitis $\mathrm{C}$ recurrence after liver transplantation: a randomized controlled study," Gastroenterology, vol. 132, no. 5, pp. 1746-1756, 2007.

[97] F. Lodato, S. Berardi, A. Gramenzi et al., "Clinical trial: peg-interferon alfa-2b and ribavirin for the treatment of genotype-1 hepatitis $C$ recurrence after liver transplantation," Alimentary Pharmacology and Therapeutics, vol. 28, no. 4, pp. 450-457, 2008.

[98] P. Sharma, J. A. Marrero, R. J. Fontana et al., "Sustained virologic response to therapy of recurrent hepatitis $\mathrm{C}$ after liver transplantation is related to early virologic response and dose adherence," Liver Transplantation, vol. 13, no. 8, pp. 1100-1108, 2007.

[99] E. Oton, R. Barcena, J. M. Moreno-Planas et al., "Hepatitis $\mathrm{C}$ recurrence after liver transplantation: viral and histologic response to full-dose peg-interferon and ribavirin," American Journal of Transplantation, vol. 6, no. 10, pp. 2348-2355, 2006.

[100] C. S. Wang, H. H. Ko, E. M. Yoshida, C. A. Marra, and K. Richardson, "Interferon-based combination anti-viral therapy for hepatitis C virus after liver transplantation: a review and quantitative analysis," American Journal of Transplantation, vol. 6, no. 7, pp. 1586-1599, 2006.

[101] S. Yedibela, D. Schuppan, V. Müller et al., "Successful treatment of hepatitis $\mathrm{C}$ reinfection with interferon- $\alpha 2 \mathrm{~b}$ and ribavirin after liver transplantation. a long-term follow-up," Liver International, vol. 25, no. 4, pp. 717-722, 2005.

[102] P. Toniutto, C. Fabris, E. Fumo et al., "Pegylated versus standard interferon- $\alpha$ in antiviral regimens for posttransplant recurrent hepatitis C: comparison of tolerability and efficacy," Journal of Gastroenterology and Hepatology, vol. 20, no. 4, pp. 577-582, 2005.

[103] S. Mukherjee, E. Lyden, T. M. McCashland, and D. F. Schafer, "Interferon alpha $2 \mathrm{~b}$ and ribavirin for the treatment of recurrent hepatitis $\mathrm{C}$ after liver transplantation: cohort study of 38 patients," Journal of Gastroenterology and Hepatology, vol. 20, no. 2, pp. 198-203, 2005.

[104] A. S. Ross, A. K. Bhan, M. Pascual, M. Thiim, A. B. Cosimi, and R. T. Chung, "Pegylated interferon $\alpha$-2b plus ribavirin in the treatment of post-liver transplant recurrent hepatitis C," Clinical Transplantation, vol. 18, no. 2, pp. 166-173, 2004.

[105] E. Giostra, G. A. Kullak-Ublick, W. Keller et al., "Ribavirin/ interferon- $\alpha$ sequential treatment of recurrent hepatitis $\mathrm{C}$ after liver transplantation," Transplant International, vol. 17, no. 4, pp. 169-176, 2004.

[106] M. Berenguer, M. Prieto, A. Palau et al., "Recurrent hepatitis C genotype $1 \mathrm{~b}$ following liver transplantation: treatment with combination interferon-ribavirin therapy," European Journal of Gastroenterology and Hepatology, vol. 16, no. 11, pp. 1207-1212, 2004.

[107] S. Nair, S. Khan, G. Loss et al., "Treatment of recurrent hepatitis $\mathrm{C}$ in liver transplant recipients: is there any histologic benefit?" Liver Transplantation, vol. 9, no. 4, pp. 354-359, 2003.

[108] A. O. Shakil, B. McGuire, J. Crippin et al., "A pilot study of interferon alfa and ribavirin combination in liver transplant recipients with recurrent hepatitis C," Hepatology, vol. 36, no. 5, pp. 1253-1258, 2002.

[109] K. V. Narayanan Menon, J. J. Poterucha, O. M. El-Amin et al., "Treatment of posttransplantation recurrence of hepatitis $\mathrm{C}$ with interferon and ribavirin: lessons on tolerability and efficacy," Liver Transplantation, vol. 8, no. 7, pp. 623-629, 2002.

[110] B. Lavezzo, A. Franchello, A. Smedile et al., "Treatment of recurrent hepatitis $\mathrm{C}$ in liver transplants: efficacy of a six versus a twelve month course of interferon alfa $2 \mathrm{~b}$ with ribavirin," Journal of Hepatology, vol. 37, no. 2, pp. 247-252, 2002.

[111] R. J. Firpi, M. F. Abdelmalek, C. Soldevila-Pico et al., "Combination of interferon alfa-2b and ribavirin in liver transplant recipients with histological recurrent hepatitis C," Liver Transplantation, vol. 8, no. 11, pp. 1000-1006, 2002.

[112] J. Dumortier, J. Y. Scoazec, F. Berger, and O. Boillot, "Recurrence of hepatitis $\mathrm{C}$ after liver transplantation: followup and treatment," Transplantation Proceedings, vol. 34, no. 3, pp. 779-781, 2002.

[113] S. Targhetta, P. Burra, A. Popovic et al., "Natural $\alpha$-IFN in HCV recurrence after liver transplantation," Transplantation Proceedings, vol. 33, no. 1-2, pp. 1457-1458, 2001.

[114] A. Kornberg, M. Hommann, A. Tannapfel et al., "Long-term combination of interferon alfa- $2 \mathrm{~b}$ and ribavirin for hepatitis $\mathrm{C}$ recurrence in liver transplant patients," American Journal of Transplantation, vol. 1, no. 4, pp. 350-355, 2001.

[115] M. E. De Vera, G. A. Smallwood, K. Rosado et al., "Interferon- $\alpha$ and ribavirin for the treatment of recurrent hepatitis C after liver transplantation," Transplantation, vol. 71, no. 5, pp. 678-686, 2001.

[116] J. Ahmad, S. F. Dodson, A. J. Demetris, J. J. Fung, and A. O. Shakil, "Recurrent hepatitis $\mathrm{C}$ after liver transplantation: a nonrandomized trial of interferon alfa alone versus interferon alfa and ribavirin," Liver Transplantation, vol. 7, no. 10, pp. 863-869, 2001.

[117] T. Bizollon, U. Palazzo, C. Ducerf et al., "Pilot study of the combination of interferon alfa and ribavirin as therapy of recurrent hepatitis $\mathrm{C}$ after liver transplantation," Hepatology, vol. 26, no. 2, pp. 500-504, 1997.

[118] J. M. Moreno Planas, E. Rubio Gonzalez, E. Boullosa Graña et al., "Peginterferon and ribavirin in patients with HCV cirrhosis after liver transplantation," Transplantation Proceedings, vol. 37, no. 5, pp. 2207-2208, 2005.

[119] M. Babatin, L. Schindel, and K. W. Burak, "Pegylatedinterferon alpha $2 \mathrm{~b}$ and ribavirin for recurrent hepatities $\mathrm{C}$ after liver liver transplantation: from a Canadian experience to recommendations for therapy," Canadian Journal of Gastroenterology, vol. 19, no. 6, pp. 359-365, 2005.

[120] G. W. Neff, M. Montalbano, C. B. O’Brien et al., "Treatment of established recurrent hepatitis $\mathrm{C}$ in liver-transplant recipients with pegylated interferon-alfa-2b and ribavirin therapy," Transplantation, vol. 78, no. 9, pp. 1303-1307, 2004.

[121] M. Berenguer, "Systematic review of the treatment of established recurrent hepatitis $\mathrm{C}$ with pegylated interferon in 
combination with ribavirin," Journal of Hepatology, vol. 49, no. 2, pp. 274-287, 2008.

[122] W. C. Lee, T. J. Wu, H. S. Chou, C. F. Lee, K. M. Chan, and S. S. Cheng, "Flexible and individualized treatment to achieve sustained viral response for recurrent hepatitis $\mathrm{C}$ in liver transplant recipients," Journal of Viral Hepatitis. In press.

[123] T. Bizollon, P. Pradat, J.-Y. Mabrut et al., "Benefit of sustained virological response to combination therapy on graft survival of liver transplanted patients with recurrent chronic hepatitis C," American Journal of Transplantation, vol. 5, no. 8, pp. 1909-1913, 2005.

[124] T. Bizollon, S. N. S. Ahmed, S. Radenne et al., "Long term histological improvement and clearance of intrahepatic hepatitis C virus RNA following sustained response to interferonribavirin combination therapy in liver transplanted patients with hepatitis C virus recurrence," Gut, vol. 52, no. 2, pp. 283-287, 2003.

[125] M. Omata, H. Yoshida, J. Toyota et al., "A large-scale, multicentre, double-blind trial of ursodeoxycholic acid in patients with chronic hepatitis C," Gut, vol. 56, no. 12, pp. 1747-1753, 2007.

[126] M. Berenguer, V. Aguilera, M. Prieto et al., "Delayed onset of severe hepatitis C-related liver damage following liver transplantation: a matter of concern?" Liver Transplantation, vol. 9, no. 11, pp. 1152-1158, 2003.

[127] L. K. Schluger, P. A. Sheiner, S. N. Thung et al., "Severe recurrent cholestatic hepatitis $\mathrm{C}$ following orthotopic liver transplantation," Hepatology, vol. 23, no. 5, pp. 971-976, 1996.

[128] D. V. Gopal and H. R. Rosen, "Duration of antiviral therapy for cholestatic HCV recurrence may need to be indefinite," Liver Transplantation, vol. 9, no. 4, pp. 348-353, 2003.

[129] Y. Takada, T. Ito, Y. Ueda et al., "Effects of double-filtration plasmapheresis combined with interferon plus ribavirin for recurrent hepatitis $\mathrm{C}$ after living donor liver transplantation," Liver Transplantation, vol. 14, no. 7, pp. 1044-1047, 2008.

[130] M. Taniguchi, H. Furukawa, T. Shimamura et al., "Impact of double-filtration plasmapheresis in combination with interferon and ribavirin in living donor liver transplant recipients with hepatitis C," Transplantation, vol. 81, no. 12, pp. 1747-1749, 2006.

[131] S. Marubashi, K. Dono, A. Miyamoto et al., "Liver transplantation for hepatitis C," Journal of Hepato-Biliary-Pancreatic Surgery, vol. 13, no. 5, pp. 382-392, 2006.

[132] J.-M. Pawlotsky and R. G. Gish, "Future therapies for hepatitis C," Antiviral Therapy, vol. 11, no. 4, pp. 397-408, 2006.

[133] J. Pawlotsky, S. Chevaliez, and J. G. McHutchison, "The hepatitis C virus life cycle as a target for new antiviral therapies," Gastroenterology, vol. 132, no. 5, pp. 1979-1998, 2007.

[134] L. Lang, "Interim results presented at EASL from PROVE 1 clinical trial of investigational drug telaprevir in patients with genotype 1 hepatitis C," Gastroenterology, vol. 132, no. 7, pp. 2283-2284, 2007.

[135] J. G. McHutchison, G. T. Everson, S. C. Gordon et al., "Telaprevir with peginterferon and ribavirin for chronic HCV genotype 1 infection," The New England Journal of Medicine, vol. 360, no. 18, pp. 1827-1838, 2009.

[136] J. G. McHutchison, M. P. Manns, A. J. Muir et al., "Telaprevir for previously treated chronic HCV infection," The New England Journal of Medicine, vol. 362, no. 14, pp. 1292-1303, 2010.
[137] C. Sarrazin, R. Rouzier, F. Wagner et al., "SCH 503034, a novel hepatitis $\mathrm{C}$ virus protease inhibitor, plus pegylated interferon alpha-2b for genotype 1 nonresponders," Gastroenterology, vol. 132, no. 4, pp. 1270-1278, 2007.

[138] S. L. Bogen, W. Pan, S. Ruan et al., "Toward the back-up of Boceprevir (SCH 503034): discovery of new extended P4-capped ketoamide inhibitors of hepatitis C virus NS3 serine protease with improved potency and pharmacokinetic profiles," Journal of Medicinal Chemistry, vol. 52, no. 12, pp. 3679-3688, 2009.

[139] I. Mederacke, H. Wedemeyer, and M. P. Manns, "Boceprevir, an NS3 serine protease inhibitor of hepatitis C virus, for the treatment of HCV infection," Current Opinion in Investigational Drugs, vol. 10, no. 2, pp. 181-189, 2009.

[140] K. Berman and P. Y. Kwo, "Boceprevir, an NS3 protease inhibitor of HCV," Clinics in Liver Disease, vol. 13, no. 3, pp. 429-439, 2009. 


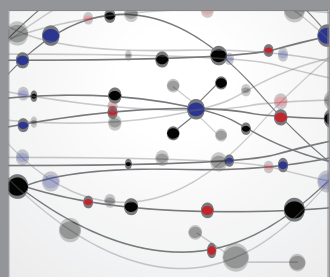

The Scientific World Journal
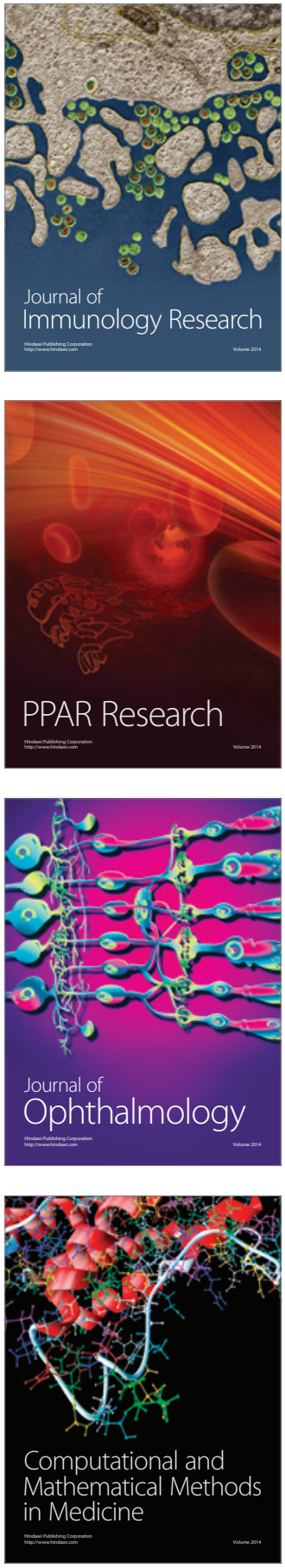

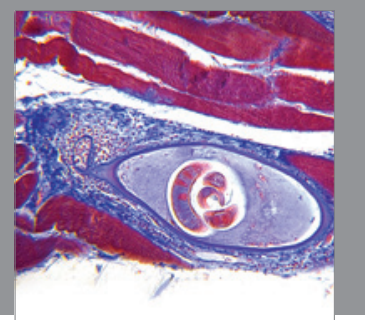

Gastroenterology

Research and Practice
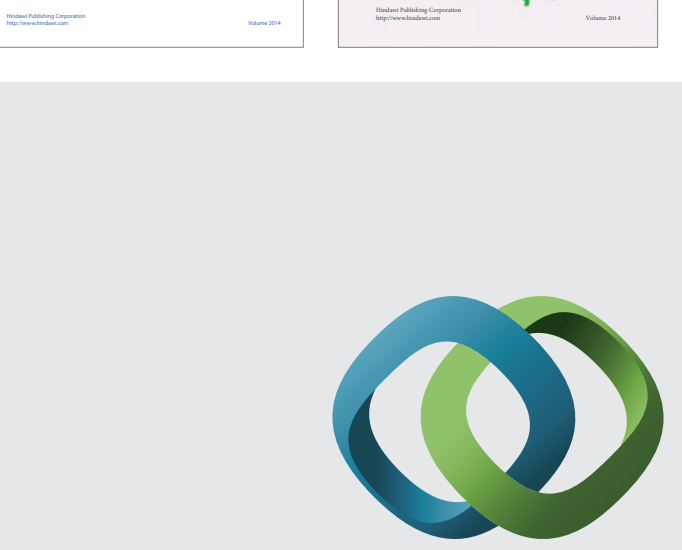

\section{Hindawi}

Submit your manuscripts at

http://www.hindawi.com
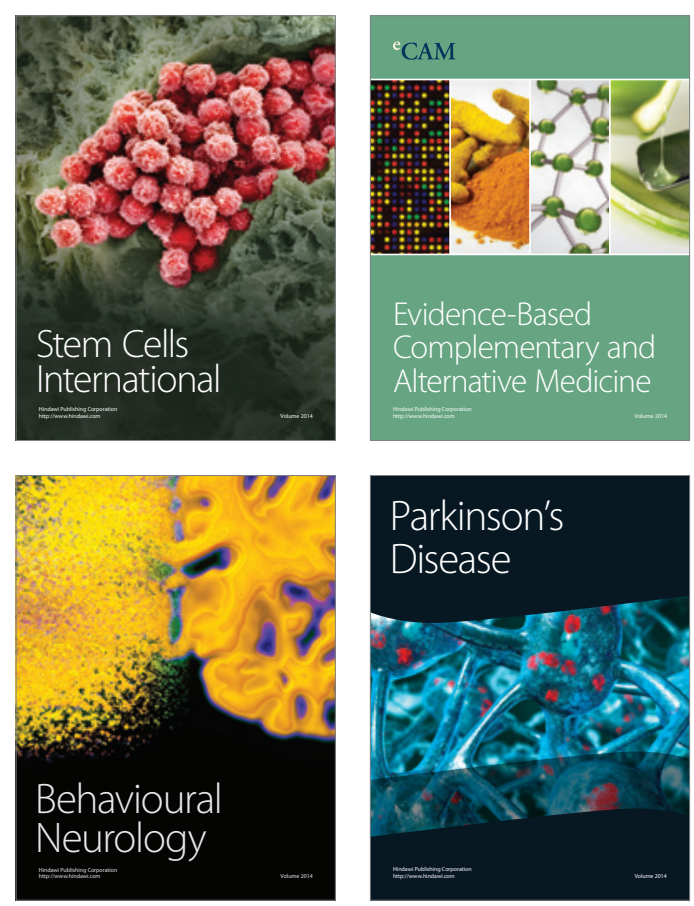

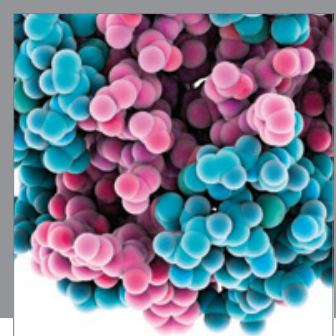

Journal of
Diabetes Research

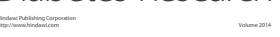

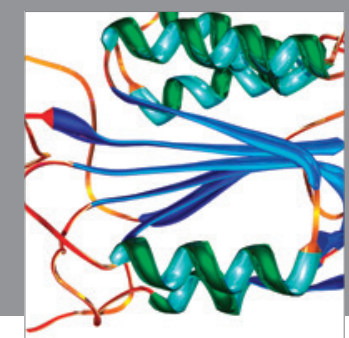

Disease Markers
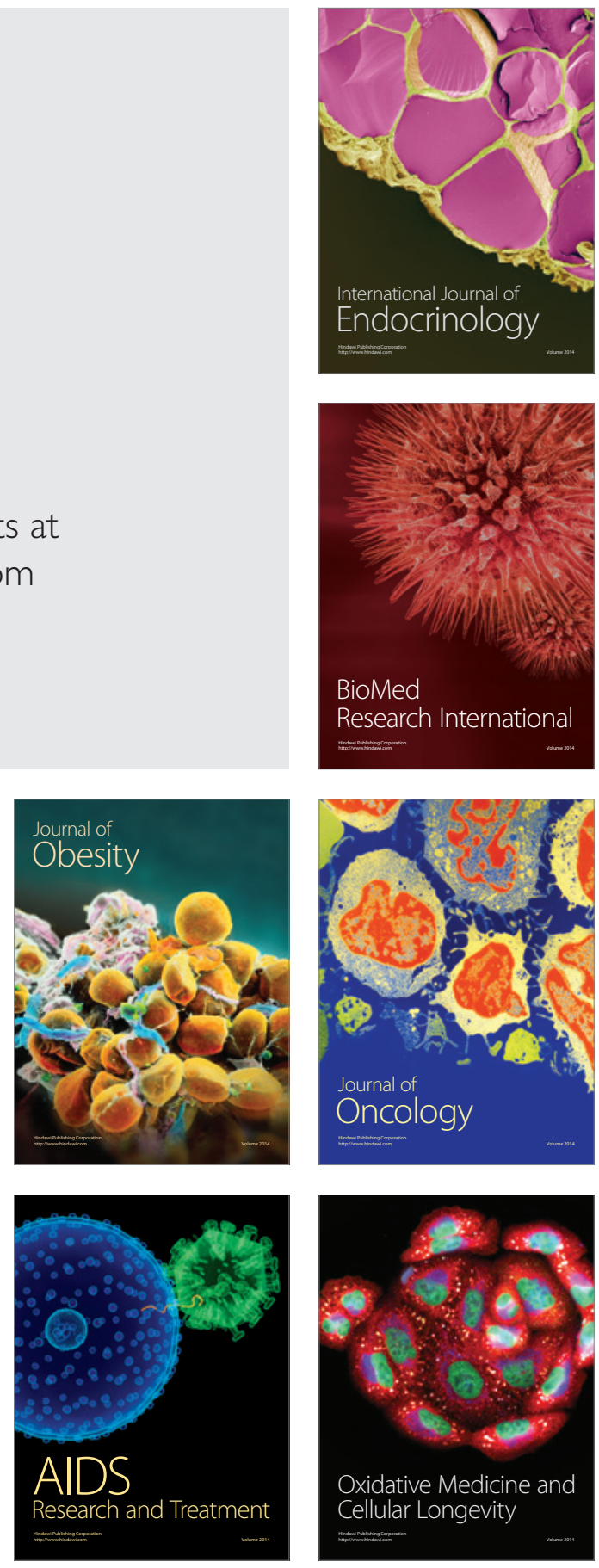